\title{
G1896A Precore Mutation and Association With HBeAg Status, Genotype and Clinical Status in Patients With Chronic Hepatitis B
}

\author{
Jeyanthi Suppiah, ${ }^{1, *}$ Rozainanee Mohd Zain, ${ }^{1}$ Norazlah Bahari, ${ }^{2}$ Salbiah Haji Nawi, ${ }^{3}$ and \\ Zainah Saat ${ }^{1}$ \\ ${ }^{1}$ Virology Unit, Institute for Medical Research, Kuala Lumpur, Malaysia \\ 2 Pathology Unit, Selayang Hospital, Selangor, Malaysia \\ ${ }^{3}$ Microbiology Unit, Hospital Kuala Lumpur, Kuala Lumpur, Malaysia \\ *Corresponding Author: Jeyanthi Suppiah, Virology Unit, Institute for Medical Research, Jln Pahang, 50588 Kuala Lumpur, Malaysia. Tel:+60-326162674, E-mail: jeyanthi@imr.gov.my \\ Received 2015 July 13; Revised 2015 August 17; Accepted 2015 August 19.
}

\begin{abstract}
Background: Precore stop codon (G1896A) mutation is one of the commonest mutations found in patients with chronic hepatitis B. However, over the years, this mutation was not reported much in Malaysia.

Objectives: We therefore investigated the presence of G1896A mutation in Malaysian population and its association with HBeAg status, clinical stage, hepatitis B virus (HBV) genotype and e-seroconversion rate.

Patients and Methods: Serum samples from 93 patients confirmed as hepatitis B carriers were collected for molecular assay. The whole genome of $\mathrm{HBV}$ was amplified by polymerase chain reaction and directly sequenced. The precore and basal core promoter regions were analyzed for presence of mutations.

Results: The most commonly observed mutation in the precore region was $1858 \mathrm{~T}$ with $64.5 \%$ prevalence. The precore mutation of interest (G1896A) was identified in $25.8 \%$ of isolates. The basal core promoter mutations detected were A1762T-G1764A (26.9\%), C1653T (8.6\%), A1752G (10.8\%) and C1766T (2.2\%). No significant association was observed between G1896A mutation and HBeAg-negativity. Nonetheless, G1896A was highly prevalent among HBV genotype B. Clinical association revealed that subjects with G1896A mutations were mainly detected in asymptomatic chronic hepatitis B (58.3\%) and liver cirrhosis (41.7\%). One subject was diagnosed with fulminant hepatitis (4.2\%) and $8.3 \%$ had hepatocellular carcinoma (HCC).

Conclusions: Our data suggested an intermediate prevalence of G1896A mutation among Malaysian hepatitis B carriers. The stop codon mutation has a significant association with genotype $B$ and patients with chronic hepatitis B and liver cirrhosis.
\end{abstract}

Keywords: G1896A, Precore, Hepatitis B, Genotype, Liver Cirrhosis

\section{Background}

Chronic hepatitis B (HB) infection is endemic in Malaysia and throughout South-East Asia. Chronic HB infection manifestation is diverse ranged from an inactive carrier status to advance stage, which may progress to cirrhosis and hepatocellular carcinoma (HCC). Chronic HB is present as either hepatitis B e antigen (HBeAg)-positive or HBeAg-negative. HBeAg is a viral protein secreted by HBV infected cells. HBeAg is thought to be an indicator of viral replication and to predict patient's degree of infectiousness, whereas presence of anti-HBe antibodies often indicates a low level of viral replication (1). The presence of HBeAg is pivotal in deciding treatment whereby oral antiviral medication is continued until HBeAg seroconversion is achieved (2).

HBV has high tendency to acquire mutations in different regions of its genome including polymerase, surface antigen, core/pre-core promoter and X gene regions. Our previous studies in Malaysia have shown drug resistance mutations in polymerase gene and $\mathrm{S}$ gene mutations of $\operatorname{HBV}(3,4)$. Further interest to investigate mutations present in the pre-core region of the virus is mainly due to the association of these mutations with development of HBeAg-negative phenotype.

A predominant mutation in the pre-core region involves a G to A change at nucleotide1896 (G1896A), which generates a premature stop codon at codon 28 (5). This mutation has crucial role in preventing translation of HBeAg and completely hampers the production of HBeAg antigen. Thus, emergence of stop codon mutation may be a means of immune evasion. In addition, a double mutation at nucleotides 1762/1764 at the core promoter region was observed to affect HBeAg production (6).

\section{Objectives}

The aim of this study was to identify the presence of G1896A mutant in HBV virus isolated from Malaysian HBV

Copyright ( ) 2015, Kowsar Corp. This is an open-access article distributed under the terms of the Creative Commons Attribution-NonCommercial 4.0 International License (http://creativecommons.org/licenses/by-nc/4.0/) which permits copy and redistribute the material just in noncommercial usages, provided the original work is properly cited. 
carriers and determine the association of this mutation with several parameters such as clinical status, genotype and HBeAg status.

\section{Patients and Methods}

\subsection{Ethics Statement}

This study obtained ethical approval from Ethics and medical research committee, ministry of health Malaysia (Reference number: NMRR-12-311-11789). The ethics committee indicated that patient consent was not required as the samples used were retrospective and confirmed as Hepatitis B carriers.

\subsection{Serum Samples}

The study included 93 retrospective blood serum samples of confirmed Hepatitis B carriers, obtained from Hospital Selayang, Kuala Lumpur, Malaysia. The samples were collected randomly regardless of age, race, sex, treatment and symptoms for a period of three years (2012 - 2014). Demographic data of patients involved in this study are indicated in Table 1.

\subsection{HBV DNA Extraction and Amplification}

HBV DNA was extracted from serum samples using High Pure Viral Nucleic Acid Extraction Kit (Roche, USA) according to the manufacturer's instructions. The $3.215 \mathrm{~kb}$ length HBV full genome was amplified using 14 sets of oligonucleotides published previously. PCR amplification using primers published by Sugauchi et al. (2001) (7) was performed by nested PCR, whereas amplification with primers published by Kahila Bar-Gal et al. (2012) (8) performed by direct PCR. All PCR conditions were performed as described by Suppiah et al. (2014) (4).

\subsection{Sequencing}

A $15 \mathrm{uL}$ aliquot of each PCR reaction was analyzed on
$2 \%$ prestained agarose by gel electrophoresis and viewed under UV illumination. The amplicons were extracted from agarose gel and purified using gel extraction kit (Qiagen, USA) according to the manufacturer's instruction. All purified PCR amplicons were subjected to cycle sequencing using corresponding sense and antisense oligonucleotides and sequenced in 3730 genetic analyzer (Applied Biosystem, USA) using standard sequencing protocol.

\subsection{Data Analysis}

The full genome of HBV was obtained by aligning overlapping sense and antisense sequences using CLUSTAL Omega tool (https://www.ebi.ac.uk/Tools/msa/clustalo/). The reference sequence used in the alignment was Hepatitis B virus isolate M1 (GenBank Accession number: GQ924603). The genotypes of Malaysian Hepatitis B carriers were determined by Genotyper bioinformatics tool and phylogenetic analysis (data published). The consensus sequences were then analyzed at the basal core promoter (BCP), precore (PC) and core (C) region and particularly observed for presence of G1986A mutation. Association of G1986A with few parameters such as HBeAg status, genotype, liver diseases and e-seroconversion rate were statistically determined by chi-square analysis.

\section{Results}

\subsection{HBV Full Genome Sequencing and Genotyping}

A total $76 \mathrm{HBV}$ complete nucleotide and 17 partial nucleotide sequences were obtained by PCR amplification and sequencing. (GenBank Accession numbers: KJ803752KJ803827). Genotyping of the full genome sequences by HEPSEQ software revealed a distribution of $49.46 \%, 48.39 \%$ and $2.15 \%$ of genotypes C, B, and D, respectively; whereas, phylogenetic and jumping profile Hidden Markov Model (jpHMM) analysis identified six (7.89\%) recombinant B/C strains (published result) (4).

\begin{tabular}{|c|c|c|}
\hline \multirow[t]{2}{*}{ Variables } & \multicolumn{2}{|c|}{ Groups } \\
\hline & With G1896A mutation, $(n=24)$ & Without G1896A mutation $(n=69)$ \\
\hline Age, $y$ & $52.3 \pm 16.3$ & $48.3 \pm 16.8$ \\
\hline Gender (Male:Female) & 13:11 & $48: 21$ \\
\hline HBV DNA copy, IU/mL & $1.24 \times 10^{7} \pm 3.39 \times 10^{7}$ & $1.16 \times 10^{5} \pm 2.53 \times 10^{5}$ \\
\hline Normal ALT level & 87.5 & 70.0 \\
\hline Elevated ALT level & 12.5 & 30.0 \\
\hline HBeAg-negative & $21(87.5)$ & $48(69.6)$ \\
\hline HbeAg-positive & $3(12.5)$ & $21(30.4)$ \\
\hline HCC & $2(8.3)$ & $11(15.9)$ \\
\hline Liver cirrhosis & $10(41.7)$ & $9(13.0)$ \\
\hline Asymptomatic CHB & $14(58.3)$ & $45(65.2)$ \\
\hline Fulminant Hepatitis B & $1(4.2)$ & $0(0)$ \\
\hline Acute Hepatitis B Flare & $0(0)$ & $3(4.3)$ \\
\hline e-seroconversion & $2(8.3)$ & $2(2.9)$ \\
\hline
\end{tabular}

${ }^{\mathrm{a}}$ Data are presented as mean $\pm \mathrm{SD}$, percent or No. (\%). 


\subsection{BCP, PC and C Region Analysis}

The most commonly observed mutation in the precore region was $\mathrm{C} 1858 \mathrm{~T}$, which comprised $64.5 \%$ of all isolates sequenced. The precore mutation of interest (G1896A) was identified in $25.8 \%$ of isolates. Among the basal core promoter mutations, A1762T-G1764A double mutation was present in $26.9 \%$, C1653T in 8.6\%, A1752G in $10.8 \%$ and C1766T in $2.2 \%$ of all isolates. Circulation of genotypes among these mutations is summarized in Table 2 .

\subsection{G1896 A Mutation in Relation to HBeAg Status}

From 93 subjects, 69 were HBeAg-negative and 24 HBeAg positive. Precore stop codon G1896A was detected in $30.4 \%$ (21/69) of HBeAg-negative subjects and $12.5 \%$ (3/24) of HBeAg-positive cases. In total, there were 24 hepatitis B infected subjects with G1896A mutant, of whom all were HBeAg-negative except three. The mutation was more prevalent in HBeAg-negative than HBeAg-positive subjects, nevertheless the difference was not statistically significant $(\mathrm{P}>0.05)$.

\subsection{Genotype and Association With G1896A Muta- tion}

Malaysian HBV isolates were clustered into genotypes C, B, recombinant $\mathrm{B} / \mathrm{C}$ and $\mathrm{D}$ with a frequency of $47.37 \%$, $43.42 \%, 7.89 \%$ and $1.32 \%$, respectively (4). It was observed that the prevalence of HBV infected subjects with G1896A mutation in genotypes $\mathrm{B}$ and $\mathrm{C}$ was comparable. The occurrence of mutation in genotype B group was $48.5 \%$ (16/33) and in genotype C group was $19.4 \%$ (7/36). Similarly, within the mutation group, genotype B was the most prevalent genotype (67\%). The precore stop codon mutation was not present in any of the recombinant $\mathrm{B} / \mathrm{C}$ genotype and there was one genotype D subject who carried the mutation. Chi-square analysis revealed a significant association between HBV genotype and G1896A mutation, whereby subjects infected with HBV genotype B had G1896A mutation more commonly $(\mathrm{P}<0.05)$.

\subsection{G1896A Mutation in Relation to Clinical Status of Subjects}

Clinical status of patients categorized into asymptomatic chronic HB, liver cirrhosis, fulminant hepatitis, hepatocellular carcinoma (HCC) and acute HB flare (Table 1). Subjects with G1896A mutations were mainly in asymptomatic chronic HB (58.3\%) and liver cirrhosis (41.7\%) groups. Fulminant hepatitis was diagnosed in one patient (4.2\%) and 8.3\% had HCC. There was a significant association between G1896A occurrence in subjects and liver cirrhosis $(\mathrm{P}<0.05)$. Though the number of subjects with fulminant hepatitis is extremely low, the only subject in the study carried the mutation. Two subjects infected with HBV and had G1896A mutation diagnosed with HCC. However, there was no statistical association between HCC and G1896A.

\subsection{G1896A Mutation and e-Seroconversion}

Three of 24 subjects with G1896A were HBeAg-positive. Among the three, two had e-seroconversion. Both subjects were male, aged 37 and 40 and diagnosed with chronic HB. Similarly, in non-mutant group, two more subjects had e-seroconversion. The electropherogram showed a heterozygous peak in the forward sequence for the two subjects with e-seroconversion. This was not observed in the subject without seroconversion where both forward and reverse sequences showed homozygous mutant peak.

\subsection{Prevalence of G1896A Mutation in Comparison to Age and Genotypes}

Age comparison among HBV patients harboring G1896A revealed that, in all 3 genotypes ( $B, C$ and $D)$, middle-aged adults (36 - 55 years old) had prominent distribution of the mutation ( $41.7 \%, 12.5 \%$ and $4.2 \%$ ), respectively. The stop codon mutation was equally observed in the geriatrics group belonging to genotypes $\mathrm{B}$ and $\mathrm{C}$ and none were found in the pediatrics group (Table 3 ).

\begin{tabular}{|c|c|c|c|c|c|c|}
\hline \multirow[t]{2}{*}{ Genotypes } & \multicolumn{2}{|c|}{ Precore Mutations } & \multicolumn{4}{|c|}{ Basal Core Promoter Mutations } \\
\hline & G1896A & C1858T & A1762T-G1764A & C1653T & A1752G & $\mathrm{C} 1766 \mathrm{~T}$ \\
\hline B & 67 & 48 & 24 & 0 & 80 & 50 \\
\hline C & 29 & 45 & 64 & 100 & 0 & 50 \\
\hline $\mathbf{B} / \mathbf{C}$ & 0 & 3 & 8 & 0 & 20 & 0 \\
\hline D & 4 & 3 & 4 & 0 & 0 & 0 \\
\hline
\end{tabular}

\footnotetext{
${ }^{\mathrm{a}}$ Data are presented as percent.
}

\begin{tabular}{|c|c|c|c|c|c|}
\hline \multirow[t]{2}{*}{ Genotypes } & \multirow[t]{2}{*}{ Paediatric $(0-17)$} & \multicolumn{3}{|c|}{ Adult (18 - 65) } & \multirow[t]{2}{*}{ Geriatrics $(\geq 66)$} \\
\hline & & Young adults ( $18-35)$ & Middle aged adults (36 - 55) & Older adults (55 - 65) & \\
\hline B & 0 & 4.2 & 41.7 & 16.7 & 4.2 \\
\hline C & 0 & 4.2 & 12.5 & 8.3 & 4.2 \\
\hline $\mathrm{B} / \mathrm{C}$ & 0 & 0 & 0 & 0 & 0 \\
\hline D & 0 & 0 & 4.2 & 0 & 0 \\
\hline
\end{tabular}




\section{Discussion}

Precore mutants of HBV caused infections difficult to treat, prolonged duration and higher risk of liver cirrhosis. These mutations include a change in DNA bases from guanine to adenine at position 1896 (G1896A), and from cytosine to thymine at position 1858 (C1858T) of the viral genome. From the analysis of the Malaysian HBV sequences, most isolates were found to confer C1858T mutation in the precore region. This finding is in agreement with reports of T1858 variant commonly found in Asian regions $(9,10)$.

Genotype predominance was not observed in subjects with C1858T mutation as it was equally distributed among HBV B and C genotypes and found in two of the D genotype. Other studies found major existence up to $100 \%$ of T1858 variant in genotypes B, D and E, moderately or heterogeneously in genotype $C$ and less common in genotype A (11-13). The mutation of interest G1896A was also present in $\mathrm{HBV}$ sequences. Interestingly, it was observed that all subjects with A1896 variant carried the T1858 variant. The T1858 substitution is known to be a provocateur of A1896 mutation that abolishes synthesis of HBeAg (14). G1896A mutation is located within the epsilon $(\varepsilon)$ structure, a highly conserved stem-loop essential for the initiation of encapsidation during viral replication (15). When G1986A mutation is paired with C1858T, the $\varepsilon$ structure is more stabilized, thus enhancing viral replication. Therefore, development of G1896A mutation relies on the presence or absence of $\mathrm{C}$ or $\mathrm{T}$ at position 1858 , which is genotype dependent $(1,16)$.

Our findings suggested that G1896A mutation was not significantly associated with HBeAg-negativity. This is contradicted by several studies reporting that A1896 variant existence is profound in HBeAg-negative subjects (1, $17,18)$. On the other hand, when HBeAg status was compared within the subjects that had A1896 mutation, a large proportion were HBeAg-negative (21/24, 87.5\%). However, when statistically determined, this association was insignificant as a large number of HBeAg-negative status was observed in the non-mutant group. Generally, a very low prevalence (0\% - 9.3\%) of A1896 variant in HBV has been observed in Malaysia since late 1990's and early 2000 's $(11,19,20)$. Furthermore, absence of HBeAg in HBV infected patients does not necessarily indicate the presence of pre-core mutant entirely.

The G1896A mutation was more prevalent in HBV genotype $B$ than genotype $C$ in Malaysia. In accordance to the finding of this study, few other countries such as Indonesia, Vietnam and East Asia reported a significant association between genotype B and G1896A mutation $(13,21,22)$. The basis behind genotype selectivity of G1896A mutant mainly points to the $\mathrm{C} 1898 \mathrm{~T}$ mutation, which is prominently present in genotypes B, D and E.

Regarding the relation of G1896A mutation and clinical status of study subjects, it was observed that the stop codon mutation was significantly present in patients with asymptomatic chronic hepatitis B and liver cirrhosis. The proportion of patients with liver cirrhosis who acquired A1896 variant in our study (41.7\%) is similar to the findings by Tong et al. (23) (42.0\%). However, the same study found a strong correlation of mutation with development of HCC, which was not observed in our study. There was one subject in the present study with fulminant hepatitis who had G1896A mutation. Association could not be drawn from this finding as the number of fulminant hepatitis in this study was limited to one. However, there have been numerous reports describing an association between precore stop codon mutation and fulminant hepatitis (24-26). G1896A was thought to cause severe liver disease as it is frequently found in patients with chronic hepatitis B, liver cirrhosis and fulminant hepatitis. Conversely, several studies detected this mutation in asymptomatic HBV carriers $(27,28)$. Thus, the role of this mutation in triggering severe form of hepatitis is unclear.

The role of G1896A mutation in HBeAg-positive seroconversion has been reported (29). In the present study, from 5 subjects with e-seroconversion, two conferred G1896A mutation. Similarity in age, gender and clinical status was observed in both patients. However, it is unclear if this mutation occurred before or after e-seroconversion. This is because retrospective samples were used in this study; therefore, no follow-up was performed for subjects. However, heterozygous A1896 and G1896 peak observed in only one sequence direction may suggest the role of G1896A in triggering e-seroconversion.

The present study also evidenced prominent prevalence of G1896A mutation among middle-aged adult group followed by older adult group and low prevalence in geriatric and pediatric groups. This finding is supported by another study that showed a high prevalence of this mutation among middle-aged patients (30). The reason for selectivity of stop codon mutation in middle-aged group is unclear. The absence of stop codon mutation among pediatric group was inconclusive as only one subject from the mentioned group was available for this study.

In conclusion, the study findings showed an intermediate prevalence of G1896A mutation among Malaysian hepatitis B carriers. No significant association was observed between G1896A mutations and its role in causing HBeAg-negativity. However, our data suggested a significant association of G1896A with genotype B and patients with chronic hepatitis B and liver cirrhosis.

\section{Acknowledgments}

The authors would like to thank the director general of health Malaysia for his permission to publish this paper. This project was funded by the ministry of health Malaysia (JPP-IMR: 12-006, NMRR-12-311-11789 and Akaun Amanah 16833).

\section{Footnotes}

Authors' Contribution:Jeyanthi Suppiah was involved in the entire study, conducting experiments, analysis 
and interpretation of data and drafting the manuscript. Rozainanee Mohd Zain delivered intellectual content to the study. Salbiah Haji Nawi and Norazlah Bahari contributed to sample provision and clinical knowledge. Zainah Saat contributed to intellectual content, study design and revision of the manuscript.

Funding/Support:This study was funded by ministry of health, Malaysia [JPP-IMR: 12-006, NMRR-12-311-11789 and Akaun Amanah16833].

\section{References}

1. Zhand S, Karami C, Adli AH, Tabarraei A, Khodabakhshi B, Moradi A. Correlation between hepatitis B G1896A precore mutations and HBeAg in chronic HBV patients. Jundishapur J Microbiol. 2015;8(2):17126. doi: 10.5812/jjm.17126. [PubMed: 25825644]

2. Nguyen MH, Keeffe EB. Are hepatitis B e antigen (HBeAg)-positive chronic hepatitis $B$ and HBeAg-negative chronic hepatitis B distinct diseases? Clin Infect Dis. 2008;47(10):1312-4. doi: 10.1086/592571. [PubMed: 18840075 ]

3. Suppiah J, Zain RM, Nawi SH, Bahari N, Saat Z. Drug-resistance associated mutations in polymerase (p) gene of hepatitis $B$ virus isolated from malaysian HBV carriers. Hepat Mon. 2014;14(1):13173. doi: 10.5812/hepatmon.13173.. [PubMed: 24497877]

4. Suppiah J, Zain RM, Bahari N, Nawi SH, Saat Z. S Gene Mutants Occurrence Among Hepatitis B Carriers in Malaysia. Hepat Mon. 2014;14(12):22565. doi: 10.5812/hepatmon.22565.. [PubMed: 25737728]

5. Carman WF, Hadziyannis S, McGarvey MJ, Jacyna MR, Karayiannis P, Makris A, et al. Mutation preventing formation of hepatitis b e antigen in patients with chronic hepatitis b infection. Lancet. 1989;334(8663):588-91. doi: 10.1016/s0140-6736(89)90713-7. [PubMed: 2570285]

6. Takahashi K, Aoyama K, Ohno N, Iwata K, Akahane Y, Baba K, et al. The precore/core promoter mutant (T1762A1764) of hepatitis B virus: clinical significance and an easy method for detection. $J$ Gen Virol.1995;76 ( Pt 12):3159-64. doi:10.1099/0022-1317-76-12-3159. [PubMed: 8847524]

7. Sugauchi F, Mizokami M, Orito E, Ohno T, Kato H, Suzuki S, et al. A novel variant genotype $C$ of hepatitis $B$ virus identified in isolates from Australian Aborigines: complete genome sequence and phylogenetic relatedness. J Gen Virol. 2001;82(Pt 4):883-92. doi:10.1099/0022-1317-82-4-883. [PubMed: 11257194]

8. Kahila Bar-Gal G, Kim MJ, Klein A, Shin DH, Oh CS, Kim JW, et al. Tracing hepatitis B virus to the 16th century in a Korean mummy. Hepatology. 2012;56(5):1671-80. doi: 10.1002/hep.25852. [PubMed: 22610996]

9. Yoo BC, Park JW, Kim HJ, Lee DH, Cha YJ, Park SM. Precore and core promoter mutations of hepatitis $\mathrm{B}$ virus and hepatitis $\mathrm{B}$ e antigen-negative chronic hepatitis B in Korea. J Hepatol. 2003;38(1):98-103. doi: 10.1016/s0168-8278(02)00349-5. [PubMed: 12480566]

10. Saha D, Pal A, Biswas A, Panigrahi R, Sarkar N, Das D, et al. Molecular characterization of HBV strains circulating among the treatment-naive HIV/HBV co-infected patients of eastern India. PLoS One. 2014;9(2):e90432. doi: 10.1371/journal.pone.0090432. [PubMed: 24587360]

11. Har TS, Meng TT, Siang KB, Zawawi M, Thanaletchimy N. Hepatitis $\mathrm{B}$ virus genotypes and pre-core/core promoter mutations in Malaysian carriers. Malaysia J Biochem Mol Biol. 2005;12(1)

12. Lindh M, Andersson AS, Gusdal A. Genotypes, nt 1858 variants, and geographic origin of hepatitis B virus--large-scale analysis using a new genotyping method. J Infect Dis. 1997;175(6):1285-93. [PubMed: 9180165]

13. Utsumi T, Aksono EB, Yano Y, Hayashi Y, et al. Predominance of precore mutations and clinical significance of basal core promoter mutations in chronic hepatitis $B$ virus infection in Indonesia. Biomed Rep. 2013;1(4):522-8. doi: 10.3892/br.2013.106. [PubMed: 24648979]

14. Yuan J, Zhou B, Tanaka Y, Kurbanov F, Orito E, Gong Z, et al. Hepa- titis B virus (HBV) genotypes/subgenotypes in China: mutations in core promoter and precore/core and their clinical implications. J Clin Virol. 2007;39(2):87-93. doi: 10.1016/j.jcv.2007.03.005. [PubMed:17451999]

15. Buckwold VE, Xu Z, Chen M, Yen TS, Ou JH. Effects of a naturally occurring mutation in the hepatitis B virus basal core promoter on precore gene expression and viral replication. J Virol. 1996;70(9):5845-51. [PubMed: 8709203]

16. Gonzalez Lopez Ledesma MM, Mojsiejczuk LN, Rodrigo B, Sevic I, Mammana L, Galdame O, et al. Hepatitis B virus genotype distribution and genotype-specific $\mathrm{BCP} /$ preCore substitutions in acute and chronic infections in Argentina. PLoS One. 2015;10(3):e0121436. doi:10.1371/journal.pone.0121436. [PubMed: 25822666]

17. Grandjacques C, Pradat P, Stuyver L, Chevallier M, Chevallier P, Pichoud C, et al. Rapid detection of genotypes and mutations in the pre-core promoter and the pre-core region of hepatitis B virus genome: correlation with viral persistence and disease severity. J Hepatol. 2000;33(3):430-9. doi: 10.1016/s0168-8278(00)80279-2. [PubMed: 11019999]

18. Triki H, Ben Slimane S, Ben Mami N, Sakka T, Ben Ammar A, Dellagi K. High circulation of hepatitis B virus (HBV) precore mutants in Tunisia, North Africa. Epidemiol Infect. 2000;125(1):169-74. [PubMed: 11057973]

19. Ton SH, Iskandar K, Noriah R, Thanaletchimy N. Nucleotide Sequence of Precore Region of Hepatitis B Virus DNA in HBsAg-positive Carriers in Malaysia. Scandinavia J Infect Dis. 1996;28(6):5438. doi:10.3109/00365549609037957.

20. Lim CK, Tan JT, Khoo JB, Ravichandran A, Low HM, Chan YC, et al. Correlations of HBV genotypes, mutations affecting HBeAg expression and HBeAg/ anti-HBe status in HBV carriers. Int JMed Sci. 2006;3(1):14-20. [PubMed:16421626]

21. Huy TT, Ushijima H, Quang VX, Ngoc TT, Hayashi S, Sata T, et al. Characteristics of core promoter and precore stop codon mutants of hepatitis B virus in Vietnam. J Med Virol. 2004;74(2):22836. doi:10.1002/jmv.20175. [PubMed: 15332271]

22. Lindh M, Hannoun C, Dhillon AP, Norkrans G, Horal P. Core promoter mutations and genotypes in relation to viral replication and liver damage in East Asian hepatitis B virus carriers.J Infect Dis. 1999;179(4):775-82. doi: 10.1086/314688. [PubMed: 10068571]

23. Tong MJ, Blatt LM, Kao JH, Cheng JT, Corey WG. Precore/basal core promoter mutants and hepatitis B viral DNA levels as predictors for liver deaths and hepatocellular carcinoma. World J Gastroenterol. 2006;12(41):6620-6. [PubMed: 17075974]

24. Chu CM, Yeh CT, Chiu CT, Sheen IS, Liaw YF. Precore mutant of hepatitis B virus prevails in acute and chronic infections in an area in which hepatitis B is endemic. J Clin Microbiol. 1996;34(7):1815-8. [PubMed: 8784599]

25. Alexopoulou A. Mutants in the precore, core promoter, and core regions of Hepatitis B virus, and their clinical relevance. Ann Gastroenterol. 2009;22(1):13-23.

26. Panassie L, Borentain P, Nafati C, Bernardin G, Doudier B, Thibault $\mathrm{V}$, et al. Fatal fulminant primary hepatitis B virus infections with G1896A precore viral mutants in southeastern France. Clin Res Hepatol Gastroenterol. 2012;36(1):e1-8. doi: 10.1016/j. clinre.2011.09.002. [PubMed: 22037043]

27. Okamoto H, Yotsumoto S, Akahane Y, Yamanaka T, Miyazaki Y, Sugai Y, et al. Hepatitis B viruses with precore region defects prevail in persistently infected hosts along with seroconversion to the antibody against e antigen. J Virol. 1990;64(3):1298-303. [PubMed: 2304145]

28. Akarca US, Greene S, Lok ASF. Detection of precore hepatitis B virus mutants in asymptomatic HBsAg-positive family members. Hepatology. 1994;19(6):1366-70. doi: 10.1002/hep.1840190608. [PubMed: 8188166]

29. Ni YH. Different hepatitis B virus core gene mutations in children with chronic infection and hepatocellular carcinoma. Gut. 2003;52(1):122-5. doi: 10.1136/gut.52.1.122. [PubMed: 12477772]

30. Kitab B, Essaid El Feydi A, Afifi R, Trepo C, Benazzouz M, Essamri $\mathrm{W}$, et al. Variability in the precore and core promoter regions of HBV strains in Morocco: characterization and impact on liver disease progression. PLoS One. 2012;7(8):e42891. doi: 10.1371/journal.pone.0042891. [PubMed: 22319637] 